\title{
A Study on Zero Offset Uncertainty on CMP 6 Pyranometer
}

\section{Krishna Raj Adhikari}

Journal of Nepal Physical Society

Volume 4, Issue 1, February 2017

ISSN : 2392-473X

\section{Editors:}

Dr. Gopi Chandra Kaphle

Dr. Devendra Adhikari

Mr. Deependra Parajuli

JNPS, 4 (1), 111-118 (2017)

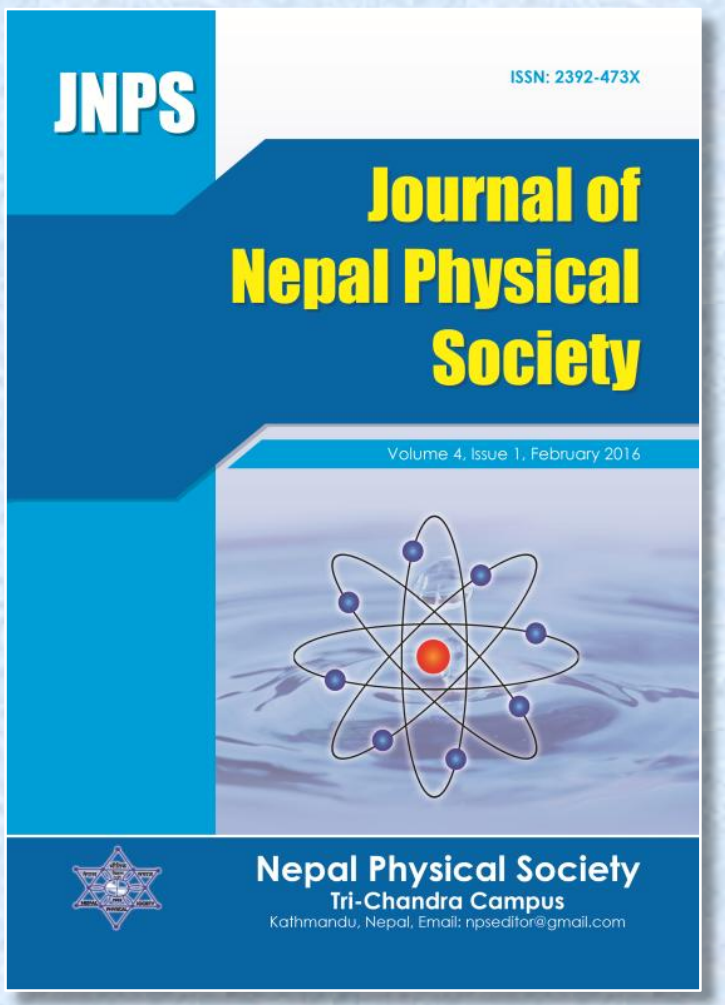

\section{Published by:}

Nepal Physical Society

P.O. Box : 2934

Tri-Chandra Campus

Kathmandu, Nepal

Email: npseditor@gmail.com 


\title{
A Study on Zero Offset Uncertainty on CMP 6 Pyranometer
}

\author{
Krishna Raj Adhikari \\ Department of Physics, Pashchimanchal Campus, IOE, Tribhuvan University, Kaski, Nepal \\ Corresponding Email: adhikarikrishna@wrc.edu.np
}

\begin{abstract}
This paper presents the zero offset in CPM6 pyranometer installed in Pokhara. In a pyranometer, a negative output called zero offset is observed when inner dome has a different temperature from the sensor and there is a net loss of energy by the pyranometer dome to the colder atmosphere which in turn is compensated by the sensor. This offset occurs due to thermal exchanges and temperature gradient within the instrument is often referred to as a zero offset, one of the uncertainties, because it becomes apparent at times when the signal should be zero. In this study, it is found that the variation of the uncertainty is independent of the day length but varies specially with climatic/weather conditions (cloud cover, wind speed, air temperature, etc) of that particular day, month, season and location. Commonly, two negative maxima were found every day; one associated with early morning hour (before sunrise) and another with evening/night before 24 hours (after sunset).
\end{abstract}

Keywords: Extraterrestrial radiation, Global solar radiation, Thermal equilibrium, Thermopile, Data logger, Zero offset.

\section{INTRODUCTION}

The major source of energy to drive living beings and atmospheric circulation in the earth is the solar energy. It is also the originator of all other sources of energy. Even the most widely used energy resources today like fossil fuels, are an indirect result of trapped Sun's energy over the time (Munawwar, 2006). The sun emits $3.9 \times 10^{26}$ Joules/second of radiation in all directions in the form of electromagnetic wave (em wave) that reach the surface of the heavenly bodies like the earth obeying the inverse square law. Visible light is the main component of the spectrum of solar radiation together with very significant amount of infrared and small part of ultraviolet that reaches the earth surface. It also consists of a very small amount of micro wave and radio waves. The variation of intensity of solar radiation with wave length and with air mass (Tonio, 2008) is shown in figure 1.

As the electromagnetic radiation traverses the space and encounters fragile blanket of the earth's atmosphere consisting of ozone, aerosol and water vapor, then it gets reflected, scattered \& absorbed and hence there occurs a considerable change/decrease in the intensity of radiation before reaching the earth surface (Iqbal, 1983; Lysko, 2006; Adhikari et al., 2013). Thus solar irradiance on the earth surface called insolation is always less than that of the upper atmosphere called extraterrestrial radiation (Iqbal, 1983).

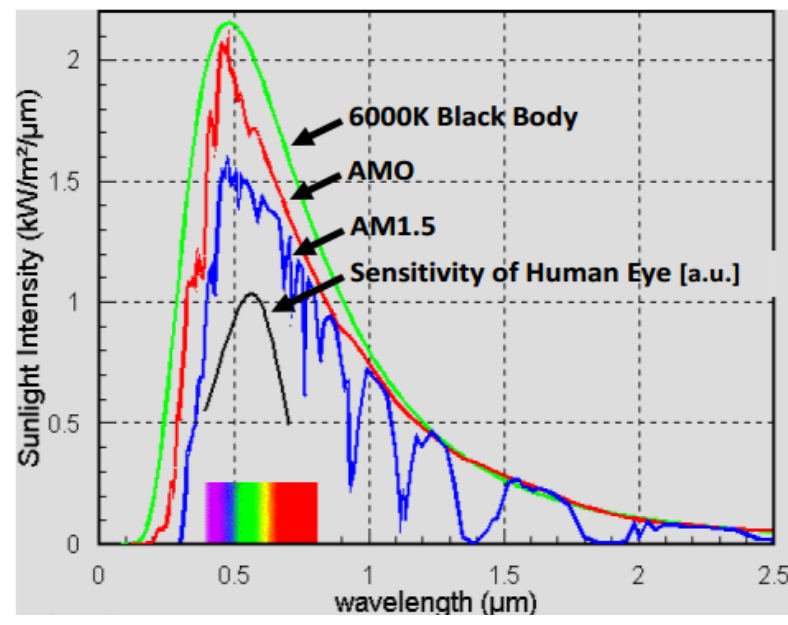

Fig.1. Variation of Solar intensity (http://www.pveducation.org/pvcdrom).

The insolation (incoming solar radiation) depends strongly on season; cloud covers of the sky, solar azimuth, latitude and altitude of the place concerned (Liou, 1982).

The solar radiation fluxes on a surface at or near the ground are importantly connected with thermal processes (Duffie and Beckman, 2006). So, the 
potential of solar radiation should be brought on surface through the measurements using suitable devices to manage and utilize properly since the calculation and prediction of solar radiation are not as easy as we think.

Among the various solarimeters basically two instruments are applied to measure solar irradiance. They are: Pyrheliometer for measuring beam (direct) radiation at normal incidence and pyranometer for measuring total or global solar (beam plus diffuse) radiations usually on a horizontal surface (Duffie and Beckman, 2006). A pyranometer can also be used in a tilted position, in which it will also receive the ground-reflected radiation. The instrument with a shading device measures the diffuse solar irradiance within a solid angle of $2 \pi$, with the exception of the solid angle subtended by the sun's disk (Iqbal, 1983).

The sensing element in solarimeter is also called detector based commonly on thermoelectric principle in most of the specified companies eg; Eppley, Kipp \& Zonenn and EKO (Lysko, 2006). Kipp and Zonen provides thermopile based latest CMP (solarimeter) and CMA (albedometer) series where CMP 6 is an ISO certified first class pyranometer featured with sixty four CopperConstantan thermocouples and (Kipp and Zonnen, 2006), originally based on Moll thermopile (Moll, 1923) as the sensing element. The hot junctions on one side of the thermopile are coated with a highly stable carbon based non organic coating; they deliver excellent spectral absorption and long term stability characteristics whereas the junctions on the other side, called cold junctions, are kept at constant low temperature.

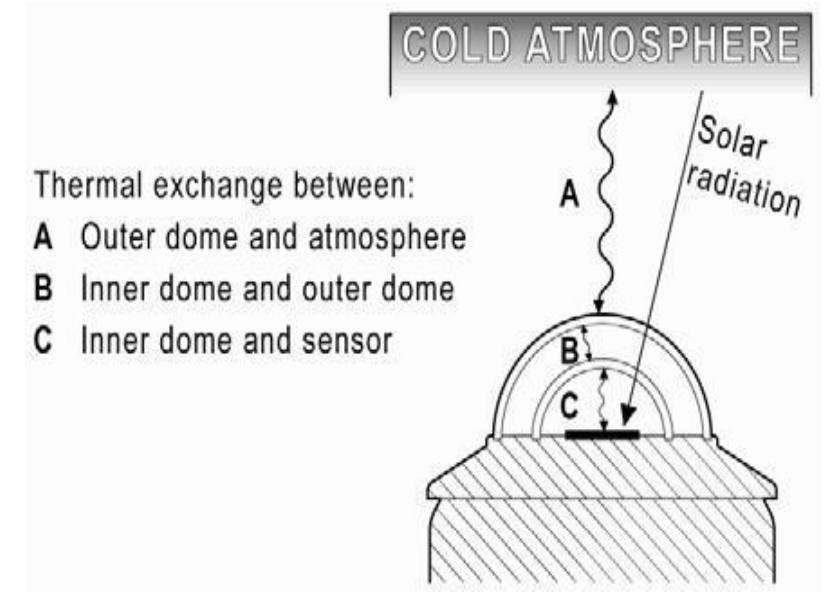

Fig. 1. Pyranometer (Curtesy: Kipp and Zonnen Online FAQ (Kipp and Zonnen)
A pyranometer, with a field of view complete sky dome, measures total solar irradiance with a good accuracy. Its temperature dependency of sensitivity $\left(-10^{0}\right.$ to $\left.+40^{\circ}\right)$ is less than $4 \%$ and operating temperature range is $-40^{\circ} \mathrm{C}$ to $80^{\circ} \mathrm{C}$ (Kipp and Zonnen, 2006). When solar radiation passes through the dome and falls on the sensing element of the pyranometer, the difference in temperature is developed between two junctions of the thermopile and hence an emf is developed. The thermo-emf is recorded by data logger and finally converted into the output in $\mathrm{W} / \mathrm{m}^{2}$ as the insolation. The positive output is observed in the presence of solar radiation which enables us to derive information about the performance of solar energy systems (Lingamgunta and Netaj, 2004) but the negative output, usually in the absence of radiation, an error related to thermal offset and zero offset, is the topic of study of this paper. The three main factors they contribute to uncertainty in the pyranometer are: instrument calibration, instrument sensitivity to its operating conditions, and thermal exchanges within the instrument (Haeffelin et al., 1999). Zero offset is related to the third one.

Prevost theory of heat exchange tells that anybody having a temperature above $0 \mathrm{~K}$ exchanges heat/radiation with its surroundings whereas net heat flow is always from a hot to the cold body. In the figure 2 the dome of the upward facing pyranometer will exchange radiation primarily with the comparatively cold atmosphere usually when there is clear sky. In general, the atmosphere will be colder than the ambient temperature and there is a net loss of radiation by the pyranometer domes to the colder atmosphere. This results into the dome cooler than the rest of the instrument so, it will gain the heat from the rest of the instrument by conduction and from the sensor by the net infrared radiation. This creates temperature difference between the sensor and inner dome and the instrument housing which generates a small negative output signal usually called thermal offset or zero offset (one of the uncertainties) since it becomes apparent at times when the signal should be zero (Dominguez, 2001; Smith, 1999).

The zero offset can be minimized by using an inner dome which acts as a 'radiation buffer', by creating good ventilation of the domes \& body or by placing a light and infrared reflecting cap over the pyranometer (Kipp and Zonnen).

This uncertainty occurs due to the constructional defect of the instrument, ambient temperature and condition of the sky which is the subject of the study. 
The present study will provide necessary information regarding the zero offset/negative data, influenced by cold atmosphere during the nights which were measured by CMP 6 pyranometers at Pokhara. The data are found to be varied greatly with the time of the day, condition/constituents of the sky/atmosphere, speed of the wind and season of the year.

The main aim of this study is to calculate and analyze the trend of diurnal variation of the zero offset for Pokhara. And it also aims to present the day of the year (DOY) when the maximum and minimum values were occurred, to suggest the coldest time of the atmosphere of that day and also to find the reason to occur the zero offset peaks usually in evening (after sunset) and in early morning (before sunrise).

\section{METHOD and METHODOLOGY}

Data of solar insolation were collected from Solar Radiation and Aerosol in Himalaya Region
(SAHR) project, Institute of Engineering, Pulchowk, Nepal. More data on global solar radiation (GSR) were obtained from the Department of Hydrology and Meteorology, Government of Nepal (DHM/GoN), Babarmahal. The data obtained covers many years but in this study, only one year 2010 data have been used for Pokhara of latitude $28.216^{\circ}$, longitude $84^{\circ}$, and altitude $827 \mathrm{~m}$ above the sea level.

\section{Theory}

Thermoelectric sensor, based on thermoelectric effect, is used in Kipp and Zonen (CMP 6) Pyranometer to sense the solar irradiance. Thus, thermo electromotive force, $\varepsilon$ is generated in the sensor of the pyranometer due to present of solar irradiance which is function of the temperature difference $\Delta \mathrm{T}$ between the hot and cold junction of the thermocouple and given by the relation

$V_{\text {emf }} \propto \Delta T$
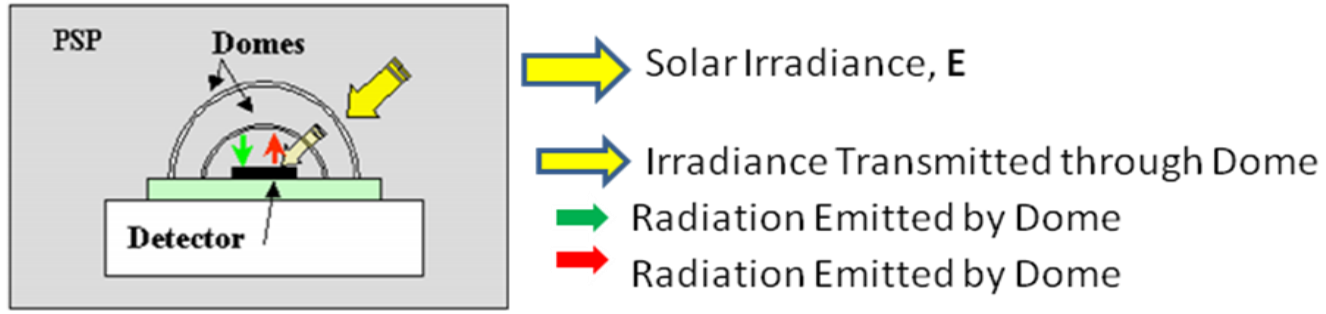

Fig. 3. Exchange of radiation (Source: (Web)

Measuring $\Delta \mathrm{T}$ is a very difficult task since measuring hot junction temperature is almost tiresome job but body and dome temperatures can be measured by setting thermistors at suitable places in pyranometer. So, Haeffelin and his team (Haeffelin, 1999) developed an analytical model of the energy balance of the pyranometer to relate the instrument temperatures to the instrument offset based on the analyses carried out for the pyrgeometer instrument by Albrecht et al. (1974),
Philipona et al., (1995) and Fairwall et al., (1998). The blackened absorber which is intimately bonded to the hot junctions is called sensor/detector, and the passive or cold junctions are in thermal contact with body of the instrument serves as a heat sink (Haeffelin, 2001). There is exchange of heat between the domes and the sensor as shown in figure 3 . The net heat radiation per second per unit area $\left(I_{\text {net }}\right)$ arriving at the sensor (Haeffelin, 1999) can be defined as

$\mathrm{I}_{\mathrm{net}}=\alpha_{s} \tau_{d} E+\alpha_{s} e_{d} \sigma T_{d}^{4}+\alpha_{s} e_{s} a_{d} \sigma T_{s}^{4}-e_{S} \sigma T_{S}^{4}$

where $\mathrm{E}$ is incident solar irradiance, $\alpha_{s} \tau_{d} E$ represents the transmitted irradiance through the dome with a transmissivity $\tau_{d}$ and absorbed by the sensor of absorptivity $\alpha_{s}$. The term $\alpha_{s} e_{d} \sigma T_{d}{ }^{4}$ is the amount of radiation emitted by the dome with an emissivity $e_{d}$ at a temperature $T_{d}$ and absorbed by the sensor. The term $\alpha_{s} e_{S} \sigma a_{d} T_{S}^{4}$ represents the amount of radiation emitted by the sensor with emissivity $e_{s}$ at a temperature $T_{s}$ reflected by the 
dome with a reflectivity $a_{d}$ and absorbed by the sensor. The term $e_{s} \sigma T_{s}^{4}$ corresponds to the amount of radiation emitted by the sensor.

Similarly, from the thermoelectric effect, we have

$$
I_{n e t}=\frac{S\left(T_{S}-T_{b}\right)}{c}=\frac{V_{e m f}}{c}
$$

(Thermoelectric effect)
Temperature of the sensor can't be measured easily, so it should be replaced by

$T_{s}=\frac{V_{e m f}}{S}-T_{b}$

where $\mathrm{S}$ is Seebeck constant, c is sensitivity of the instrument, $T_{s}$ is temperature of the sensor and $T_{b}$ is the temperature of the pyranometer body. Solving above equations, we have

$$
E=V_{\text {emf }}\left[\frac{1}{c \alpha_{s} \tau_{d}}+\frac{4 e_{s} \sigma}{S \alpha_{s} \tau_{d}}\left(1-\alpha_{s} a_{d}\right) T_{b}^{3}\right]+\frac{e_{s} \sigma}{\alpha_{s} \tau_{d}}\left(1-\alpha_{s} a_{d}\right) T_{b}^{4}-\frac{e_{d} \sigma}{\tau_{d}} T_{d}^{4}
$$

Applying Kirchhoff's law, we have

$$
E=V_{e m f}\left[\frac{1}{c \alpha_{s} \tau_{d}}+\frac{4 \sigma}{S \tau_{d}}\left(1-\alpha_{s} a_{d}\right) T_{b}^{3}\right]+\frac{e_{d} \sigma}{\tau_{d}}\left(e_{s} T_{b}^{4}-T_{d}^{4}\right)+\frac{\sigma}{\tau_{d}}\left(1-\alpha_{s}\right) T_{b}^{4}
$$

when $\mathrm{E}$ is zero (at night time), it creates temperature gradient between the inner dome and the sensor which finally develops the negative output or thermal/zero offset.

Assuming $\alpha_{s} \approx 1=e_{s} \quad$ then we have

$$
\frac{V_{\text {emf }}}{S}=-\frac{e_{d}}{\tau_{d}}\left(T_{b}^{4}-T_{d}^{4}\right)
$$

which is zero offset in the pyranometer.

\section{RESULTS AND DISCUSSION}

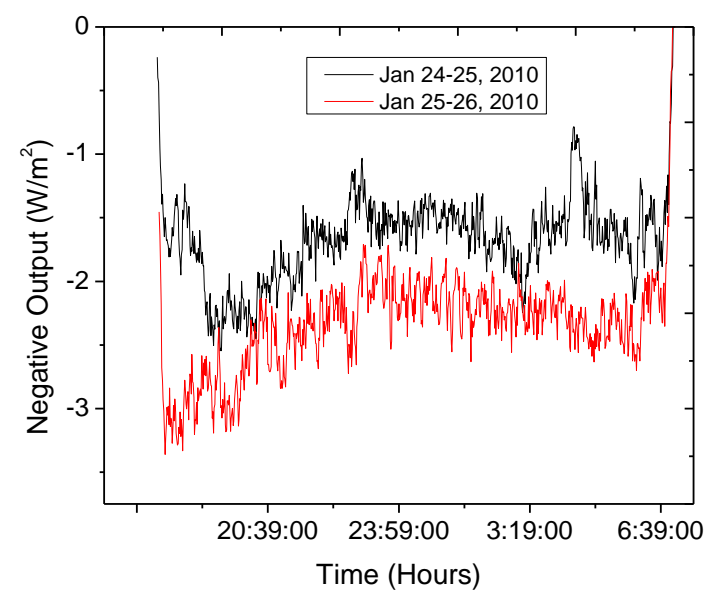

Fig. 4. (i) Zero offset plot of Jan. in minute resolution.

Relatively maximum zero offset of the three days each of twelve months of the year 2010 for Pokhara stations were plotted and shown in figures 4 . The
Thus, zero offset $\propto\left(T_{b}{ }^{4}-T_{d}^{4}\right)$

The insolation data in $\mathrm{W} / \mathrm{m}^{2}$ is recorded in the LOGBOX SD data logger within a minute resolution for 24 hours in the given sites.

The data provided by SAHR were processed in Microsoft office excel sheet, the negative output data were extracted from the data sheet, and finally fed to Origin 8.5 to plot and analyze the data.

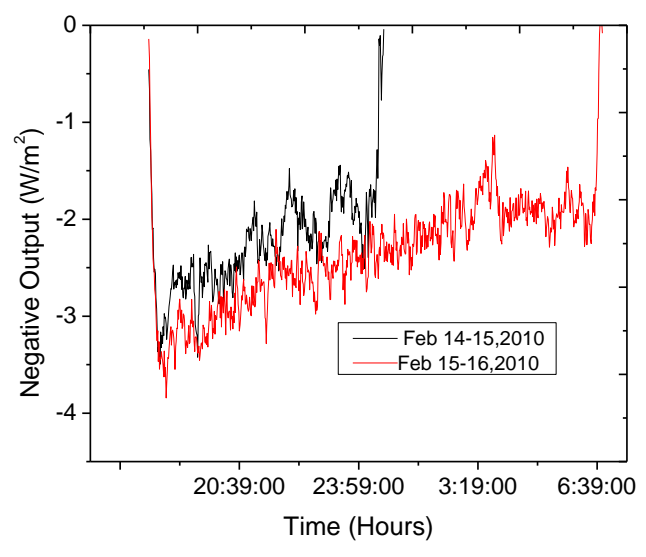

Fig. 4. (ii) Zero offset plot of Feb. in minute resolution.

graphs show that maximum zero offset of -7.105 $\mathrm{W} / \mathrm{m}^{2}$ at $20: 37$ hours on $28^{\text {th }}$ July. The findings from the graphs shown in figure 4 have been 
discussed as: a) the maximum value is not necessary to occur (i) on a day in winter season and (ii) in the early hour in the morning of that particular day, b) there were normally two peaks of zero offset on each day; one peak associated with early morning (i.e. before sunrise) and another with

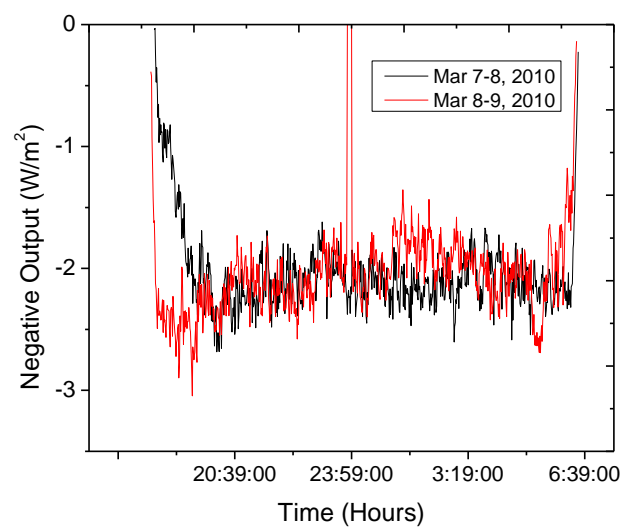

Fig. 4. (iii) Zero offset plot of March in minute resolution.

In the absence of any radiation incident on the detector i.e. usually after sunset, hot and cold junctions of the thermopile are in the thermal equilibrium so the voltage signal is zero/minimum (Dominguez, 2001). Because of high thermal conductivity and thermal mass of the detector \& body of the instrument than the dome, the detector

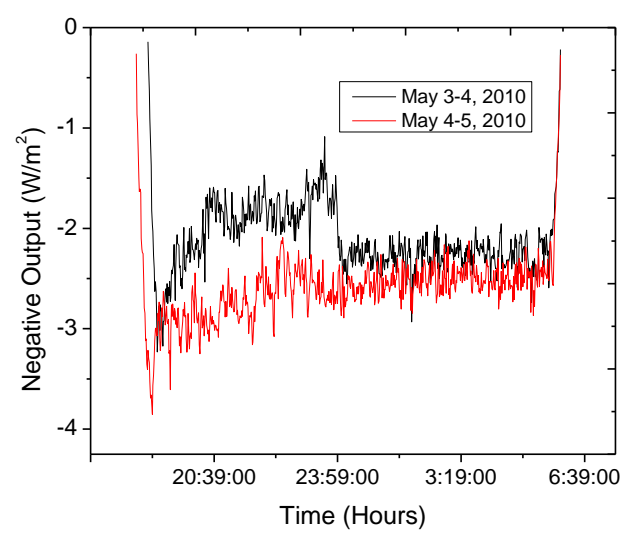

Fig. 4. (v) Zero offset plot of May in minute resolution.

Maximum value of zero offset at a time or on a day signifies that there were clear sky and less value of evening/night before 24 hours (i.e. after sunset), and c) the negative output readings were usually started from after sunset, i.e., 16:00 (in Winter) to 18:00 hour (in Summer) and continuing at 05:00 (in Summer) to 07:00 hour (in Winter) of the following day.

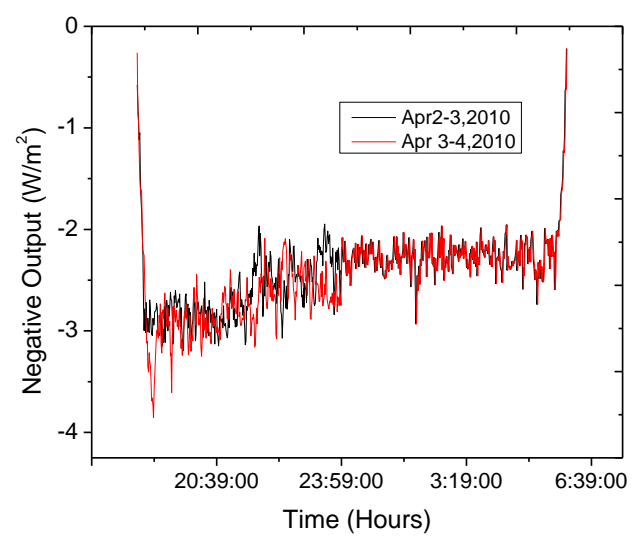

Fig. 4. (iv) Zero offset plot of April in minute resolution.

exchanges infrared radiation with the inner dome which generates zero/thermal offset i.e. uncertainty. Therefore, maximum offset in a year does not depend on the day length, month and season but depends on the condition of the sky i.e. cloud cover, speed of the wind and moisture in the atmosphere/sky.

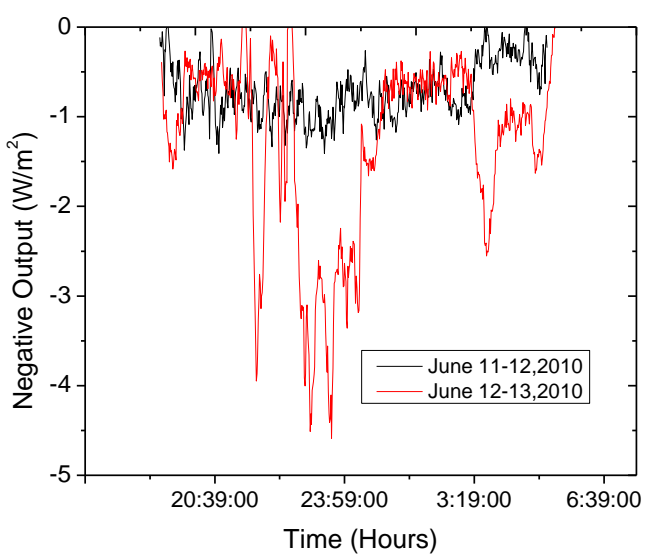

Fig. 4. (vi) Zero offset plot of June in minute resolution.

wind speed at that particular time and during that particular night on that day of the year. 


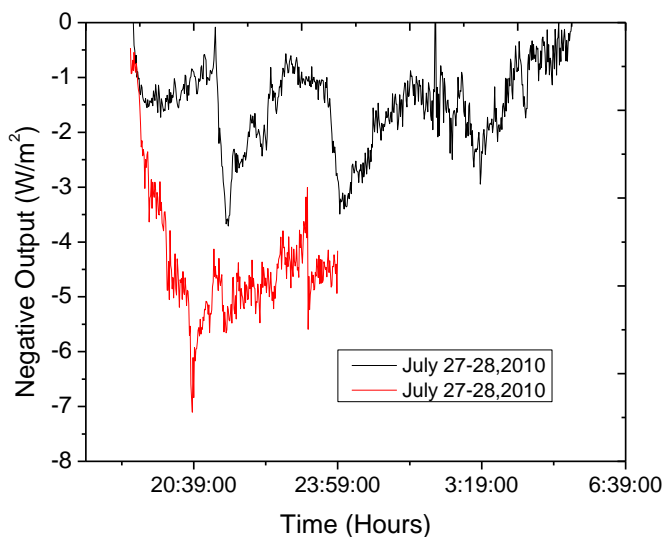

Fig. 4. (vii) Zero offset plot of July in minute resolution.

Moreover ups and downs of the curves indicate the significantly variation of body temperature because of wind, rain or atmospheric condition. And almost horizontal nature of the curve(s) indicates the

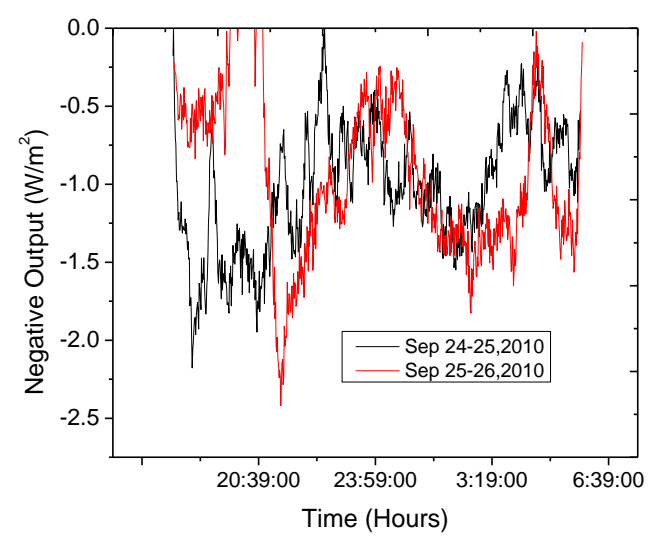

Fig. 4. (ix) Zero offset plot of Sept. in minute resolution.

\section{CONCLUSIONS}

I have studied thermal offset especially zero offset, during nighttime, recorded by CMP 6 pyranometer for Pokhara of the years 2010. There were commonly two maxima on every day where one is associated with early hours of the day and another with evening after sun set/night before 24 hours. The maximum zero offset $-7.105 \mathrm{~W} / \mathrm{m}^{2}$ is observed at $20: 37$ hours on $28^{\text {th }}$ July. The negative output readings were usually started from 16:00 to18:00 hours and ended at 05:00 to

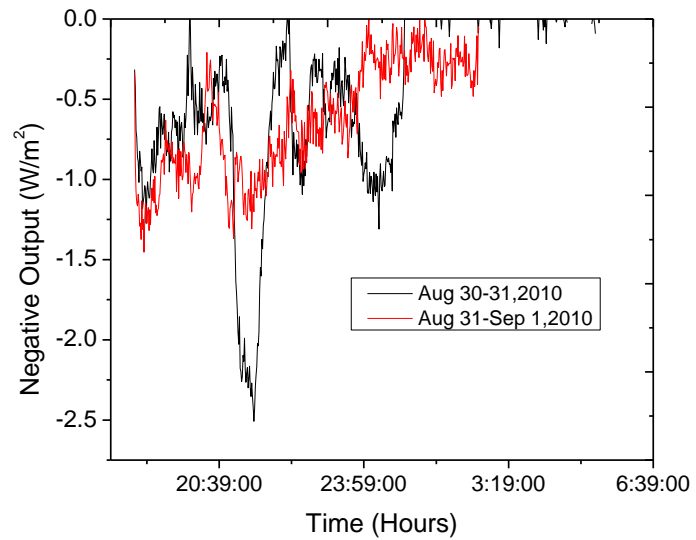

Fig. 4. (viii) Zero offset plot of August in minute resolution.

smooth change in temperature due to less wind speed, no rainfall situations and steady atmospheric conditions.

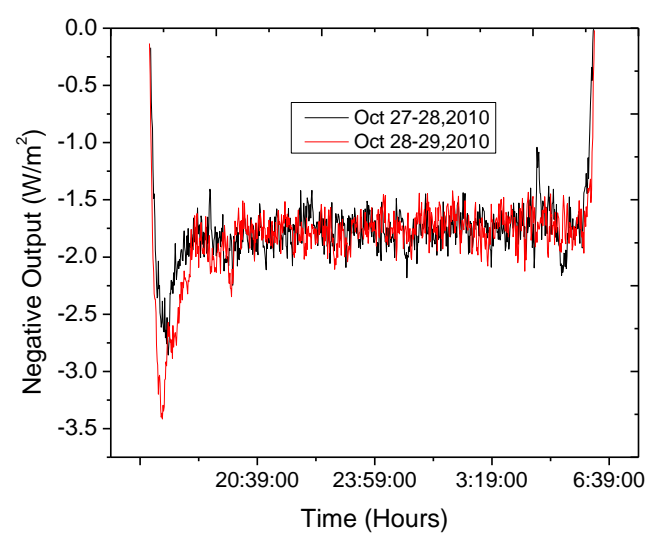

Fig. 4. (x) Zero offset plot of Oct. in minute resolution.

07:00 hours in early morning of the following day.

In the absence of any radiation incident on the sensor i.e. usually after sunset, the hot and the cold junctions of the thermopile are in the thermal equilibrium so the voltage signal is zero/minimum. Because of high thermal conductivity and high specific heat capacity of the sensor and body of the instrument than the dome, the sensor exchanges infrared radiation with the inner dome which generates zero offset uncertainty. 


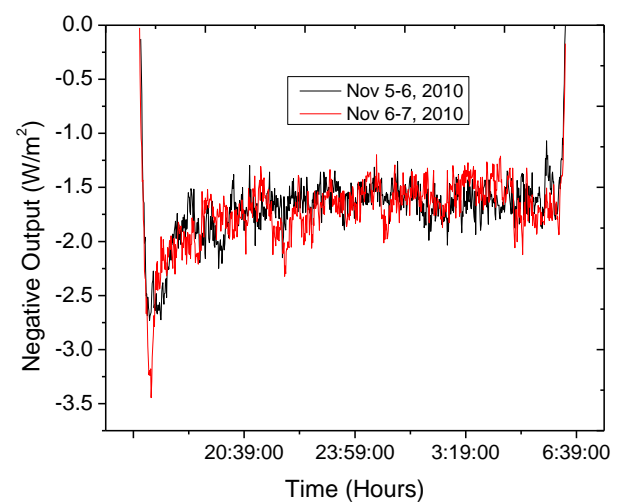

Fig. 4. (xi) Zero offset plot of Nov. in minute
resolution.

Initially the rate of cooling of domes is faster and the rate of cooling of the sensor (at higher temperature than the dome at the sun set) is slower which creates greater value of temperature gradient within the instrument and hence emits the maximum infrared radiation that is registered as the maximum negative output in data logger. After this phenomenon the temperature gradient between sensor and inner dome/body of the instrument slightly decreases and remains almost same. This process continues till the early morning of the following day before the earth surface temperature is minimal at which the next peak is observed.

The plots show the significant fluctuation in negative output from day to day and month to month. Maximum negative output on a day indicates a clear sky during night on that particular day and minimal value indicates the relatively cloudy sky, and wind blowing situations.

The instantaneous and hourly maximum negative output in a year do not depend on the day length, month and season but depends on condition or weather condition of the sky on the day and site concerned.

Moreover, it is recommended that i) determination/ estimation of ambient temperature of the location(s) concerned would be possible after measuring the negative output value read out by a pyranometer set up at that particular location(s) which is not done in this study and ii) study the characteristics of thermocouple at very low temperature situation.

\section{ACKNOWLEDGEMENTS}

University Grants Commission, Nepal is acknowledged for partial financial support. I would like to express my sincere thank to Prof. Dr.

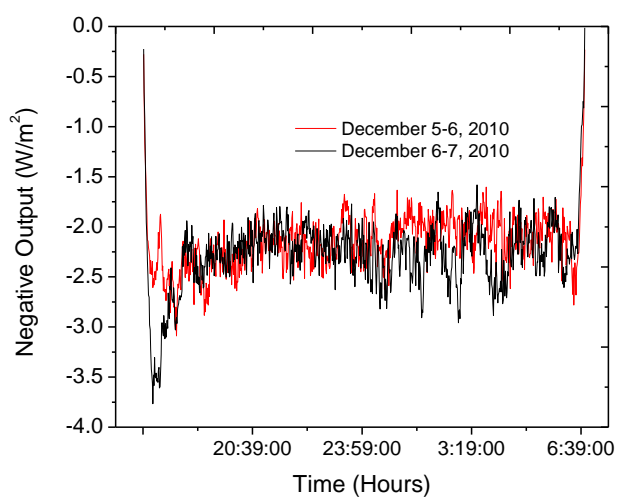

Fig. 4. (xii) Zero offset plot of Dec. in minute resolution.

Shekhar Gurung and Prof. Dr. Binod K. Bhattarai for their support and inspiration. I am indebted to Solar Radiation and Aerosol in Himalaya Region (SAHR) project, Pulchowk, Nepal and Department of Hydrology and Meteorology/GoN for the data.

\section{REFERENCES}

Adhikari, K. R.; Gurung, S., and Bhattarai, B. K. (2013). Estimation of Global Solar Radiation for Four Selected Sites in Nepal using Sunshine Hours, Temperature and Relative Humidity. Journal of Power and Energy Engineering, 1(3): 1-9.

Albrecht, B.; Peollet, M., and Cox S. K. (1974). Pyrgeometer measurements from aircraft. Rev. Sci. Instrum., 45:33-38.

Dominguez Bernardo A. Carnicero (2001). Characterization of Pyranometer Thermal Off-set and Correction of Historical Data, Master's Thesis, Faculty of the Virginia Polytechnic Institute and State University, Blacksburg, Virginia.

Duffie, J. A. and Beckman W. A. (2006). Solar Engineering of Thermal Process. Third ed., John Willey and Sons, New York.

Fairall, C. W.; Persson P. O. G.; Bradley E. F., Payne R. E., and Anderson S. P. (1998). A new look at calibration and use of Eppley precision infrared radiometers, Part I: Theory and application. J. Atmos. Ocean. Tech., 15:1229-1242.

Haeffelin, M. P.; Rutledge C. K.; Kato S.; Smith A. M., Mahan, J. R. (1999). Surface shortwave radiation measurements: Experimental tests and numerical simulations of pyranometers, 
Proceedings of the $9^{\text {th }}$ Annual ARM Science Team Meeting San Antonio, TX, March 2326.

Haeffelin, M.; Kato S.; Smith A. M.; Rutledge C. K.; Charlock T. P., and Mahan J. R. (2001). Determination of the thermal offset of the Eppley precision spectral pyranometer. Optical Society of America, 40:472-484.

http://scholar.lib.vt.edu/theses/available/etd06282001-131406/unrestricted/Chapter3.pd.

Iqbal, M. (1983). An Introduction to Solar Radiation, Academic Press, New York.

Kipp and Zonnen. On the history of pyranometer. http://www.kippzonen.com/? news/290202/On the history of pyranometer. aspx

Kipp and Zonnen. History. http://www.kippzon. com/\%3Fpage/37172/History.aspx

Kipp and Zonnen. Online FAQ data base of Kipp and Zonnen. http://www.kippzonen.com

Kipp and Zonnen (2006). CMP/CMA Series Instruction Manual, Kipp \& Zonen B.V. Delftechpark 36, 2628 XH Delft, The Netherlands.

Lingamgunta, C.; Netaj, V. T. (2004). A Universal Relationship for Estimating Clear Sky Insolation. Energy Conversion Management, 45: $27-52$.
Liou, K. N. (1982). An Introduction to Atmospheric Radiation. Second ed., Academic Press, New York.

Lysko, M. D. (2006). Measurements and Models of Solar Irradiance, Doctoral Thesis, Norwegian University of Science and Technology, Faculty of Natural Sciences and Technology, Department of Physics, Trondheim.

Moll, W. J. H. (1923). A thermopile for measuring radiation. Proc. Phys.Soc. London, Ser. B, 35:257-260.

Munawwar, S. (2006). Modeling Hourly and Daily Diffuse Solar Radiation using World-wide Database. PhD Thesis, Napier University.

Philipona, R.; Frohlich, C., and Betz, C. (1995). Characterization of pyrgeometers and the accuracy of atmospheric long-wave radiation measurements. Applied Optics, 34:15981605.

Pyranometer Protocol, David Books, IESRE. http://www.pyranometerprotocol.htm.

Smith, A. (1999). Prediction and measurement of Thermal Exchanges within Pyranometers, Master's thesis, Virginia Tech Master of Science in Mechanical Engineering.

Tonio, B. (2008). Fundamentals of Photovoltaic, Solar Resource Lecture 1-2:626. 